\title{
Herpetic Whitlow: An Occupational Hazard for Anesthesia Providers
}

\section{Barry N. Swerdlow, MD*}

Nurse Anesthesia Program, Oregon Health \& Science University

Department of Anesthesiology, Perioperative and Pain Medicine, Stanford University School of Medicine,USA.

*Corresponding Author: Barry N. Swerdlow, MD, Nurse Anesthesia Program, Oregon Health \& Science University, Department of Anesthesiology, Perioperative and Pain Medicine, Stanford University School of Medicine,USA.

\section{Abstract}

Herpetic whitlow (HW) is a herpes simplex virus (HSV) infection of the hand, usually of the distal phalanx soft tissue adjacent to the nail. The disease can be acquired by contact with infected oral mucous membranes, saliva, or respiratory secretions that harbor the virus. HSV then enters the digital skin via a clinical or subclinical abrasion in the epidermis. As such, HW is an occupational hazard for anesthesia providers - in addition to several other healthcare professions - associated with recurrent unprotected or inadequately protected hand exposure to oral mucosa and secretions, and as such, it is largely preventable. The widespread problem of unhygienic habits involving lack of glove usage or improper usage among anesthesia providers likely fosters the occurrence of HW in this population, and this behavior is partly related to the frequent need to perform multiple airway-associated interventions in a timely manner in many anesthesia practices. Despite its causal relationship with the practice of clinical anesthesia, there has been very little discussion of this disease process in the anesthesia literature during the past two decades, and this absence of an academic forum may relate to a more generalized insensitivity of many anesthesia providers to some occupational hazards of their profession.

Keywords: Herpetic whitlow; Herpes simplex; Occupational hazard; Anesthesia.

\section{INTRODUCTION}

Although the practice of anesthesia is associated with the numerous physical, chemical and biological hazards, most anesthesiologists remain remarkably uniformed about the nature of these issues and the means available for self-protection [1]. Recently, a survey of a large anesthesia cohort from a tertiary care hospital documented the common lack of knowledge among anesthesia providers concerning the methods of prevention of occupational accidents, and the frequent lack of observance of those methods [2]. For example, in the latter study, an astounding 53\% of anesthesiologists did not use gloves when securing intravenous access.

Failure to use gloves (and/or incorrect glove use) during airway manipulation by anesthesiologists is also remarkably widespread [3-6]. The relatively high prevalence of HW among anesthesia providers is likely a consequence of both the nature of the profession (in so far as frequent contact with patient oral mucosa and airway secretions is unavoidable) and the lack of correct glove use. Multiple attempts by professional organizations and governmental agencies to modify hand hygiene among anesthesiologists have been made in order to decrease the nosocomial spread of disease - including the American Society of Anesthesiologists (ASA), the Anesthesia Patient Safety Foundation (APSF), and the American Association of Nurse Anesthetists (AANA) - and some of these suggested changes also may decrease the transmission of HSV and the incidence of HW in these providers at risk $[7,8]$.

\section{PATHOPHYSIOLOGY}

In adults, HW can be caused by either HSV-1 or HSV-2 [9-13]. The primary clinical presentation of these two viruses is identical, although HW associated with HSV-2 is more likely to recur $[9,14]$. Nosocomial transmission of virus to healthcare workers in HW 
is largely due to HSV-1 (which is considerably more common than HSV-2 in the oral cavity) and the mechanism of viral transference is from oral mucosa or airway secretions to providers' digits [15].

Both HSV-1 and HSV-2 are alphaherpesviruses with no animal reservoirs. Infection with these viruses occurs via attachment to cellular co-receptors from the tumor necrosis factor receptor or nectin family of proteins that are ubiquitous and present in multiple cell types including sensory neurons - a process implicated in neuronal infection and latency [15]. During occupational exposure to HSV, abrasion of a healthcare provider's digit allows virus to enter the cells of the epidermis and dermis where it initially replicates, usually without initial clinical manifestations $[10,15,16]$. Virions then traverse the neuroepithelial gap, infect local neuronal cells, and thereafter are transported transaxonally to sensory and autonomic ganglia nerve cell bodies where they replicate extensively [15]. At this point, HSV spreads to adjacent skin surfaces via centrifugal migration of virus through peripheral sensory neural structures producing clinical primary infection often distal to the initial inoculation site [15]. Latency results from virus harbored in the sensory dorsal root ganglia (a potential haven from immune clearance), and recurrence of $\mathrm{HW}$ at intervals after the primary infection may be triggered by numerous events and constitutes a potential lifelong problem [9].

Occupational HW occurs following transmission of HSV to healthcare providers during digital contact of infected oral mucosa or secretions [9]. This sequence necessitates a break in the recipient's digital skin, which may not be apparent at the time of infection [17]. Subclinical or asymptomatic HSV shedding in the oral cavity occurs commonly, and undoubtedly relates to the unknowing contact of anesthesia providers with these pathogens $[15,18]$. Such shedding characterizes both immunocompetent and immunocompromised hosts, and can occur for days even in the presence of antiviral therapy $[15,19]$.

HSV infection is cytolytic, and viral replication in the digital skin results in the development of intraepidermal blisters. These blisters have a distinctive histology showing acantholysis, with loss of cohesion resulting in solitary keratinocytes within the lesions' cavities. The cells display reproducible changes on light microscopy with nuclear inclusions, marginalization of nuclear chromatin, and the development of hallmark fused multinucleated giant cells. Cytoplasmic alterations with vacuolation of basal keratinocytes also characterize the early phase of many HW infections. A mixed inflammatory infiltrate occurs at some point during clinical infection [20].

\section{EPIDEMIOLOGY}

HSV-1 - the pathogen causing most, if not all, occupational HW - is extremely widespread, with $90 \%$ of adults having antibodies to this virus by 50 years of age [15]. $2.5 \%$ of adult saliva contains HSV that can be identified [9], although this figure may be considerably higher in hospitalized patients. For example, $6.5 \%$ of patients with tracheostomies have been documented to have HSV in their bronchial secretions $[10,14]$, and while less common, HW likely may result from contact with infected respiratory contents (in addition to oral contents) [17,21].

The incidence of HW in the general population is relatively low - 2.4 cases per 100,000 individuals per year [11]. However, its incidence among health care workers exposed to mucous membranes and oral/respiratory secretions as part of their daily professional routine is thought to be higher. The fraction of all HW that occurs in this latter population (i.e. due to occupational exposure) has been estimated to be approximately $8 \%$ [11].

\section{Clinical Presentation and Natural HisTORY}

Following inoculation, HW blisters appear after a variable interval of time (2-20 days) [9], often on the terminal phalanx of the thumb, index, or long finger near the nail $[11,14]$ - although any anatomical region of the hand may be affected [11,14,22-24]. Infection most commonly involves the pulp of the finger [10]. Usually the lateral aspect of one finger is affected, but HW of more than one finger can also occur $[25,26]$. These skin lesions have a clear or pale yellow appearance on an erythematous base (Figure 1). The occurrence of a single vesicle or cluster of vesicles is often preceded by prodromal symptoms consisting of digital pain or tingling $[27,28]$, and a subset of patients have flulike symptoms before their eruption $[14,23,29]$ - although notable fever or significant systemic symptoms are uncommon.

Appearance of the HW vesicles may be preceded by local tenderness prior to the eruption [10,30]. During 
their initial stages, HW lesions are associated with severe local pain. Dermatomal pain or radicular pain in the forearm may also be present during this acute phase of infection, as can epitrochlear and/or axillary lymphadenopathy and lymphangitis [14,22-24,31]. In fact, lymphatic involvement occurs relatively frequently with both primary and recurrent HW, and persistent lymphedema has been described [10].

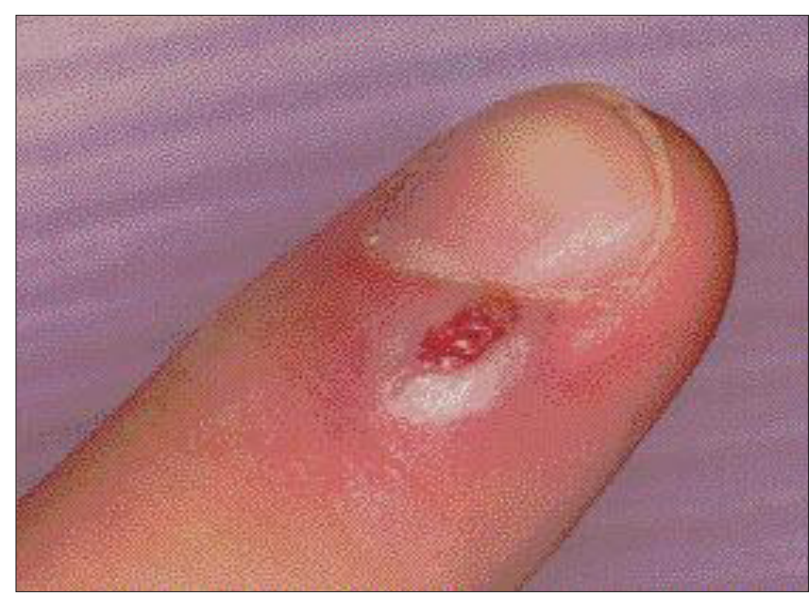

Figure 1. Herpetic whitlow of a finger. Note the lesion's yellowish appearance on an erythematous base. In this case, there is a shallow ulceration on the surface of the blister. Reproduced from [27] with permission.

After HW's initial appearance, more vesicles arise in the same area and may coalesce into a single honeycomb-like bulla (termed a "whitlow" [10]) resembling a felon[32]. Unlike this latter condition, however, tension in the pulp space of the infected finger in HW is usually not increased unless bacterial superinfection occurs $[14,22,24]$. For this reason, the pain is often out of proportion to the clinical appearance of the eruption [17].

During the first two weeks after onset of clinical disease, vesicles spread by outcroppings around the nail folds. They may undermine nails - and involve the nail bed - or spread proximally. Shallow ulcerations associated with these lesions may arise. With time, the clear vesicular fluid usually turns turbid or hemorrhagic, but not purulent unless bacterial infection has occurred. After approximately two weeks, lesions stop spreading, pain abates, and vesicles begin to form a crust. This event marks the end of viral shedding [33]. Remaining dried skin may peel off to leave healed epidermis. Affected nails also will shed and regrow [10].

HW is a self-limiting disease [17], and its natural history involves complete resolution of lesions within three weeks [14,22,29,34-36]. Rare complications include systemic viremia (potentially with meningitis; more common in immunocompromised patients), ocular infection, and local issues including nail changes, hyperesthesia or hypoesthesia $[23,35,37,38]$. HW recurs after a latent phase in $20-50 \%$ of patients $[22,23,35]$. The precise pathophysiology of this event is not understood, but recurrence is associated with general illness, fever, sun exposure, menstruation, and physiologic and/or psychological stress [9]. These episodes are usually less intense than the primary infection, and often preceded by a prodrome of distal digital pain, itching, or irritation. Recurrent eruptions may occur at the same site as the primary event, or involve a new site [9].

\section{Diagnosis}

The differential diagnosis of distal finger lesions similar to HW includes bacterial infections of the same tissues - namely bacterial felon (fingertip pulp infection), fingertip cellulitis, and bacterial paronychia (infection where skin meets nail) [16]. As previously noted, compared with a bacterial felon, HW is usually not swollen (i.e. pain out of proportion to clinical findings; the finger does not have a "drumstick" appearance) [32]; fingertip cellulitis, unlike HW, is not vesicular and involves proximal extension of soft tissue swelling; and in contrast to bacterial paronychia, HW often involves more than one lesion.

If the clinical diagnosis is unclear, several laboratory investigations may be helpful. These tests include (1) viral culture (the most sensitive diagnostic assay) and (2) serum antibody titers [9]. Since both of these assays require days to weeks for results, neither is a practical method to distinguish a bacterial infection from a viral process. Alternatively, (3) a Tzanck smear demonstrating multinucleated epithelial giant cells scraped from the base of an unroofed vesicle or ulceration debrided of crust can be suggestive of an HSV infection, but the finding is not diagnostic - since this histopathology is present with varicella zoster infections as well. The latter assay has a sensitivity of 50-60\%. Lastly, (4) testing vesicle fluid or scrapings for HSV antigen allows early diagnosis of HW, with $70-80 \%$ sensitivity. Optimally, a less mature vesicle is chosen for sampling, since viral shedding occurs early in the disease process [9]. 


\section{THERAPY}

Because the acute course of HW is self-limiting, its treatment is largely symptomatic, involving immobilization, elevation, and analgesics. For immunocompetent hosts, a course of oral acyclovir 200 milligrams ( $\mathrm{mg}$ ) five times daily for 7-10 days is recommended to shorten the duration and intensity of the disease [15]. For immunocompromised individuals, oral acyclovir $400 \mathrm{mg}$ four times daily or famciclovir $500 \mathrm{mg} 3$ times daily or oral valacyclovir $1 \mathrm{mg}$ daily is prescribed, except for severe cases where intravenous acyclovir $5 \mathrm{mg} /$ kilogram every 8 hours is preferred (7-10 day course) [15]. Oral acyclovir may also be employed to suppress reactivation of HW [38]. Incision and drainage of lesions is contraindicated and may result in superinfection [32].

\section{FACTORS ASSOCIATED WITH HW ACQUISITION By Anesthesia Providers}

Digital contact with oropharyneal mucosa, saliva, or respiratory secretions is the basis for occupational acquisition of $\mathrm{HSV}$ resulting in HW, and as such anesthesia providers are at increased risk for developing this problem $[21,28,36,40]$. Wearing gloves while handling or suctioning oral secretions or performing tracheal toilet has been emphasized as a means to prevent HW in healthcare workers $[10,14,17,41,42]$. Despite this fact, gloves are significantly under-utilized by anesthesia personnel when performing airway interventions. A relatively recent study involving anesthesia care at a tertiary medical center showed that a shocking $65 \%$ of anesthesia providers did not use gloves during intubation or laryngeal mask airway (LMA) insertion, $68 \%$ did not wear gloves for extubation, and $74 \%$ did not wear gloves for LMA removal during 1,240 observations of such events[3]. In the latter investigation, only $11 \%$ of attending anesthesiologists used gloves appropriately. Gloves also may develop cracks and tears, and thereby serve as ineffective barriers against viral inoculation [43].

Such lack of adequate hand protection by anesthesia providers makes digital HSV acquisition possible when hands are placed in contact with a patient's oropharynx (or nasopharynx), an event that occurs as a routine part of most general anesthesia inductions. This latter process often involves opening a patient's mouth for placement of an airway device (oropharyngeal airway (OPA), LMA, or endotracheal tube (ETT)) or suctioning of the oral cavity. Many general anesthetics involve opening of the mouth more than once. Mouth opening is commonly performed using either a "scissoring" technique or by depressing the patient's chin. When employing either technique, the anesthesia provider's hand often touches the patient's lip mucosa and/or oral secretions. In patients with hypersalivation, contact with secretions can occur even during uninterrupted facemask ventilation. Insertion and removal of airway devices similarly exposes anesthesia providers' hands to contact with oral mucosa and secretions on a routine basis.

While not wearing gloves for these interventions clearly potentiates nosocomial transmission of disease (both to and from the patient) and reflects substandard infection control, in order for HSV to infect a practitioner's hands resulting in HW, a digital skin abrasion must exist. Many such abrasions, however, are asymptomatic and subclinical $[14,30,35]$. For example, minor nail trauma can allow HSV to penetrate epidermis and initiate infection [16]. Unfortunately, partly as a result of repetitive opening of glass medication ampules, it is common for anesthesia providers to have minor cuts on their digital skin surface. In addition, the prevalence of cracked dry skin from repeated occlusive glove use and latex allergy is comparatively high in anesthesia providers (the latter condition occurring in approximately $2.5 \%$ of anesthesiologists [44]). The combination of an increased frequency of cutaneous abrasions and frequent unprotected (or less than fully protected) contact with patients' oral mucosa and secretions is a reasonable explanation for the increased propensity for HW in the anesthesia population.

An additional potential source of exposure of anesthesia personnel to HSV results from frequent cross contamination of anesthesia equipment with patient oral secretions. HSV can survive as an infectious agent for a variable length of time (4.5 hours to 8 weeks) on inanimate surfaces, andespecially under conditions of minimal humidity as exist in most operating rooms $[45,46]$ - these survival times are more than sufficient to allow transmission of infectious agent to the unprotected hands of an anesthesia provider when anesthesia workstation surfaces and/or equipment are contaminated with HSV. Multiple studies have documented precisely such contamination to be commonplace [4-6].

Double gloving has been shown to reduce this incidence, but even with double gloving during Archives of Anesthesiology V3 . I1 . 2020 
anesthesia induction (a technique that is practiced by a minority of anesthesia providers, and that has been publicly decried in the anesthesia community [42]), there is a $20 \%$ or greater incidence of contamination of workstation items after airway interventions [4]. For this reason, the Society for Healthcare Epidemiology of America (SHEA) - in conjunction with the ASA, APSF, and AANA - recommends complete glove removal and appropriate hand hygiene after airway manipulation prior to touching any surface [7]. The most common equipment contaminated in this manner includes the adjustable pressure-limiting (APL) valve, vaporizer, and the breathing reservoir. This data derives from a study that was performed in operating rooms where two anesthesia providers always were present during induction (one managing medications and one involved with the airway), and - probably for this reason - in this investigation, cross contamination involving the medication cart and intravenous (IV) setup (stopcock, roller clamp, and IV bag) was not seen. Because many anesthesia providers manage all aspects of induction without assistance, these latter areas most likely experience cross contamination with a frequency comparable to the anesthesia machine and breathing reservoir.

Part of the reason that anesthesia providers frequently manipulate their surroundings with hands unchanged after contact with patient oral mucosa and secretions relates to their need to perform a series of time sensitive actions during induction that involve both patients' airways and the elements of their workstation, often in a variable order. For example, if an OPA is inserted during induction, usually the provider's dominant hand (and possibly the non - dominant hand as well) contacts the patient's oral mucosa and/or secretions, but then one hand returns to manage the breathing reservoir thereafter. This same hand may then manipulate the vaporizer, APL valve, and/or oxygen, air, or nitrous oxide flow knobs-depending on the patient's anesthetic and hemodynamic requirements. Similar contact with these workstation elements often occurs following hand contamination during other airway interventions. Likewise, if critical aspects of the monitor system need attention during induction (e.g. an alarm sounds or there is an interruption in monitoring function) or additional drugs need to be obtained from the medication cart, use of a contaminated hand potentially may transfer HSV to other elements of the anesthesia work environs.
Because a patient's respiratory and hemodynamic status may change abruptly and unpredictably during induction of general anesthesia, this hand choreography may be performed at an "allegro" tempo, or at minimum without adequate focus on the hazards of cross contamination. The fact that beginning anesthesia practitioners do not have wellchoreographed induction sequences may explain - at least in part - the higher degree of contamination of the anesthesia workspace seen with these individuals [4]. Regardless, use of a practitioner's contaminated hand (i.e. without glove or without appropriate glove removal following an airway manipulation) to manage components of the anesthesia workstation creates a potential for subsequent transfer of HSV to that same practitioner's (or other practitioners') hands.

\section{ConClusion}

HW is an occupational disease of anesthesia providers associated with a painful self-limited clinical course that is subject to superinfection and relatively infrequent more serious complications. The differential diagnosis of this condition includes bacterial infections of the phalanx. HW's major morbidity usually relates to disease recurrence at intervals in $20-50 \%$ of individuals. In anesthesia personnel, this condition is likely acquired by unprotected or inadequately protected hand manipulation of HSV-containing patients' oral mucosa, saliva, and/or respiratory secretions, with transmission into the digital tissue via subclinical or clinical skin abrasions. Common unhygienic practices, including lack of appropriate glove usage and cross contamination of elements of the anesthesia workstation during airway manipulation, likely contribute to the preponderance of HW in anesthesia providers.

\section{REFERENCES}

[1] Swerdlow B. Surgical smoke and the anesthesia provider. J Anes 2020 https://doi.org/10.1007/ s00540-020-02775-x.

[2] Kim DD, Kimura A, Pontes DKL, Oliveira MLS, Cumino DO. Evaluation of anesthesiologists' knowledge about occupational health. BMC Anesthesiol. 2018;18: 1-5.

[3] Goudra B, Singh PM, Galvin E. Comparison of compliance of glove use among anesthesia providers: a prospective blinded observational study. AANA J. 2014;82: 363-367. 
[4] Jaffe G, Moriber N. Use of a double gloving technique to decrease cross-contamination by anesthesia providers. AANA J. 2019;87: 307312.

[5] Birnbach DJ, Rosen LF, Fitzpatrick M, Carling P, Arheart KL, Munoz-Price LS. Double gloves: a randomized trial to evaluate a simple strategy to reduce contamination in the operating room. Anesth Analg. 2015;120: 848-852.

[6] Biddle C, Robinson K, Pike B, Kammerman M, Gay B, Verhulst B. Quantifying the rambunctious journey of the anesthesia provider's hands during simulated, routine care. Am J Infect Control. 2016;44: 873-878.

[7] Munoz-Price LS, Bowdle A, Johnston BL, Bearman G, Camins BC, Dellinger EP, Geisz-Everson MA, Holzmann-Pazgal G, Murthy R, Pegues D, Prielipp RC, Rubin ZA, Schaffzin J, Yokoe D, Birnbach DJ. Infection prevention in the operating room anesthesia work area. Infect Cont \& Hosp Epidemiol. 2019;40: 1-7.

[8] Munoz-Price LS, Birnbach DJ. Hand hygiene and anesthesiology. Int Anesthesiol Clin. 2013;51: 79-92.

[9] Rubright JH, Shafritz AB. The herpetic whitlow. J Hand Surg Am. 2011;36: 340-342.

[10] Giacobetti R. Herpetic whitlow. Int J Dermatol. 1979;18: 55-58.

[11] Gill MJ, Arlette J, Buchan K. Herpes simplex virus infection of the hand. Am J Med. 1988; 84: 89-93.

[12] Nahmias AJ, Roizman B. Infection with herpes simplex virus types 1 and 2. N Engl J Med. 1973;289: 667-674.

[13] Wolontis S, Jeanson S, Correlation of herpes simplex virus types 1 and 2 with clinical features of infection. J Infect Dis. 1977;135: 28-33.

[14] Stern H, Elek SD, Millar Dm, Anderson HF. Herpetic whitlow: a form of cross-infection in humans. Lancet. 1959;2: 871-874.

[15] Schiffer JT, Corey L. Herpes simplex virus. In: Bennett JE, Dolin R, Blaser MJ. (eds.) Mandell, Douglas, and Bennett's principles and practice of infectious disease $\left(9^{\text {th }}\right.$ edn.). Philadelphia: Elsevier; 2020. p.1828-1848.
[16] Arora R, Chattopadhyay S, Agrawal S, Chatterjee S. Self-inflicted herpetic whitlow. BMJ Case Rep. 2014; doi:10.1136/bcr-2013-201817.

[17] Vellar, ID, Goldwasser N, Morrison W. Herpetic whitlow. Med J Aust. 1979;1: 349-350.

[18] Mark KE, Wald A, MagaretAS, SelkeS, Olin L, Huang ML, Corey L. Rapidly cleared episodes of herpes simplex virus reactivation in immunocompetent adults. J Infect Dis.2008;198: 1141-1149.

[19] Mark KE, Wald A, Magaret AS, Selke S, Kuntz S, Huang ML, Corey L. Rapidly cleared episodes of oral and anogenital herpes simplex virus shedding in HIV-infected adults. J A c q u i $r$ Immune Defic Syndr. 2010;54: 482-488.

[20] Karre T. Herpes virus infections. In: Procop, GW, Pritt, BS. (eds.) Pathology of infectious diseases. Philadelphia: Saunders; 2015. p.17-36.

[21] Jones JG. Herpetic whitlow: an infectious occupational hazard. J Occup Med. 1985; 27: 725-728.

[22] Fowler JR. Viral infections. Hand Clin. 1989;5: 613-622.

[23] Feder HM, Long SS. Herpetic whitlow: clinical characteristics, diagnosis, and treatment. AM J Dis Child. 1983;137: 861-863.

[24] Weinstein L, Artenstein MS, Plaut ME. Herpes simplex virus infections of fingers (herpetic whitlow). BMQ. 1962;13: 103-106.

[25] Smith E, Hallman JR, Pardasani A, McMichael A. Multiple herpetic whitlow lesions in a patient with chronic lymphocytic leukemia. Am J Hem. 2002;69: 285-288.

[26] Pechere M, Friedli A, Krischer J. Panaris multiples a herpes simplex type 1. Ann Dermatol Venereol. 1999;126: 646.

[27] Neville BW, Damm DD, Allen CM, Chi AC. Viral infections. In: Neville BW, Damm DD, Chi AC. (eds.) Color atlas of oral and maxillofacial diseases ( $1^{\text {st }}$ edn.). Philadelphia: Elsevier; 2019. p.141-168

[28] Klotz RW. Herpetic whitlow: an occupational hazard. AANA J. 1990;58: 8-13.

[29] Carter S, Mersheimer WL. Infections of the hand. Orthop Clin North Am. 1970;3: 455-466. 
Herpetic Whitlow: An Occupational Hazard for Anesthesia Providers

[30] LaRossa D, Hamilton R. Herpes simplex infections of the digits. Arch Surg. 1971;102: 600-603.

[31] Hurst LC, Gluck R, Sampson SP, Dowd A. Herpetic whitlow with bacterial abscess. J Hand Surg. 1991;16: 311-314.

[32] Rerucha CM, Ewing JT, Oppenlander KE, Cowan WC. Acute hand infections. Am Fam Physician. 2019;99: 228-236.

[33] Walker BW. Getting the lowdown on herpetic whitlow. Nursing. 2004;34: 17.

[34] Carter S. Herpetic whitlow: herpetic lesions of the digits. Invited comments. J Hand Surg.1979;4: 93-94.

[35] Haedicke GJ, Grossman AI, Fisher AE. Herpetic whitlow of the digits. J Hand Surg. 1989;14: 443-446.

[36] Louis D, Silva JJ. Herpetic whitlow: herpetic infection of the digits. J Hand Surg. 1979;4: 90-93.

[37] Wu IB, Schwartz RA. Herpetic whitlow. Cutis. 2007;79: 193-196.

[38] Karpathios T, Moustaki M, Yiallouros P, Sarifi F, Tzanakaki G, Fretzayas A. HSV-2 meningitis disseminated from a herpetic whitlow. Paediatr and Int Child H. 2012;32: 121-122.

[39] Laskin OL. Acyclovir and suppression of frequently recurring herpetic whitlow. Ann Int Med. 1985;102: 494-495.
[40] Orkin FK. Herpetic whitlow - occupational hazard to the anesthesiologist. Anesthesiology. 1990;33: 671 - 673 .

[41] Rosato FE, Rosato EF, Plotkin SA. Herpetic paronychia - an occupational hazard of medical personnel. N Engl J Med. 1970;283: 804-805.

[42] Orkin FK. Herpetic whitlow (editorial). N Engl J Med. 1975;292: 648-649.

[43] Mazam S. Fatigue resistance of medical gloves. J Rubber Res. 2002;5: 65-83.

[44] Hepner DL, Castells MC. Latex allergy: an update. Anes Analg. 2003;96: 1219-1229.

[45] Kramer A, Schwebke I, Kampf G. How long do nosocomial pathogens persist on inanimate surfaces? A systematic review. BMC Infect Dis. 2006;6: 130.

[46] Public Health Agency of Canada. Pathogen safety data sheets: infectious substances herpes simplex virus. Available from: https:// www.canada.ca/en/public- health/services/ laboratory-biosafety-biosecurity/pathogensafety-data-sheets-risk- assessment/herpessimplex-virus.html [Accessed $1^{\text {st }}$ May 2020].

Citation: Barry N. Swerdlow, MD. Herpetic Whitlow: An Occupational Hazard for Anesthesia Providers. Archives of Anesthesiology. 2020; 3(1): 20-26

Copyright: (C) 2020 : Barry N. Swerdlow, MD. This is an open access article distributed under the Creative Commons Attribution License, which permits unrestricted use, distribution, and reproduction in any medium, provided the original work is properly cited. 